\title{
Geometria na educação infantil: abordagem em livros didáticos integrados
}

Anaelize dos Anjos Oliveira

Cristiane Azevêdo dos Santos Pessoa

\section{Resumo}

O presente estudo teve como objetivo investigar o trabalho com Geometria em livros didáticos integrados da Educação Infantil. Para isso, buscamos identificar e analisar os tipos e a frequência das atividades relacionadas a este eixo da Matemática trabalhadas em três coleções integradas de livros didáticos deste nível de ensino. Os resultados apontam que tais livros trabalham a Geometria a partir das dimensões constituintes do campo geométrico, defendidas no presente estudo como a organização do esquema corporal, a orientação e a percepção espacial e as figuras e formas. Contudo, concluímos que mesmo trabalhando na perspectiva do ensino destas competências, as coleções, de um modo geral, apenas identificam como sendo de Geometria as atividades que trabalham com as figuras bidimensionais e tridimensionais e as transformações geométricas.

Palavras-chave: Geometria. Livro didático. Educação Infantil. 


\title{
Geometry in children education: approach in integrated didactic books
}

Anaelize dos Anjos Oliveira

Cristiane Azevêdo dos Santos Pessoa

\begin{abstract}
The present study aimed to investigate the work with Geometry in integrated didactic books of Children Education. For doing so, the types and frequency of Geometry activities were identified and analyzed in three integrated collections of didactic books in this level of teaching. The results show that these books work with Geometry through the dimensions which constitute the geometric field, defended on this study, such as the organization of the corporal scheme, spatial perception and orientation, figures and shapes. Nevertheless, we have noticed that even when working with Geometry in the perspective of teaching these competences, the collections identify/validate as mathematical contents or make explicit in the Space and Shape axis, bidimensional and tridimensional figures and geometric transformations.
\end{abstract}

Keywords: Geometry. Didactic Book. Children Education. 


\section{Introdução}

A criança, desde muito cedo, interage constantemente com o mundo físico, no qual vivencia inúmeras experiências e a partir delas constrói um mundo de ideias e conceitos importantes para resoluções de problemas de um modo geral. Assim, compreende-se que a criança chega ao ambiente escolar com uma diversidade de conhecimentos e que os mesmos devem ser valorizados na construção de novos.

Documentos curriculares nacionais como a Base Nacional Curricular Comum BNCC (BRASIL, 2017), os Parâmetros Curriculares Nacionais - PCN (BRASIL, 1997) e o Referencial Curricular Nacional para a Educação Infantil - RCNEI (BRASIL, 1998), além de autores que discutem o trabalho com a Geometria desde a Educação Infantil (EI) como Piaget e Inhelder (1993), Cerquetti-Aberkane e Berdonneau (1997), Smole, Diniz e Cândido (2003) vêm defendendo a construção de conhecimentos geométricos a partir das relações e interações da criança com o espaço. Nesta perspectiva, torna-se relevante o trabalho com as dimensões constituintes do eixo geométrico, como a organização do esquema corporal, a orientação e a percepção espaciais e as noções geométricas relacionadas às figuras.

Neste contexto, o ensino de Geometria é ampliado e ultrapassa a ideia restrita do trabalho apenas com a identificação e a nomeação de figuras bidimensionais e tridimensionais. O ensino e a aprendizagem de Geometria se voltam para o desenvolvimento integral da criança, são favorecidos ambientes que permitem a construção dessas relações com o mundo ao seu redor. Segundo Pires, Curi e Campos (2001), é ampliando suas vivências com o meio e seus objetos que a criança construirá mais conhecimentos referentes à localização, orientação e, consequentemente, a representação do espaço, distanciando-se, assim, do espaço sensorial e constituindo o pensamento geométrico ${ }^{20}$.

Silva, Silva e Pessoa (2014) ao investigarem o ensino de Geometria por professores da EI, a partir de observações de aulas e entrevistas, evidenciram um trabalho intencional apenas com as figuras bidimensionais e tridimensionais. As pesquisadoras apontam, ainda, que durante as observações das aulas, as professoras trabalharam noções de organização do esquema corporal, orientação e localização espaciais por meio de brincadeiras e atividades relacionadas à outras disciplinas, mas não demonstraram perceber que estas atividades são de Geometria. Assim, percebe-se que há o desenvolvimento de práticas de ensino que se voltam para as dimensões geométricas defendidas neste estudo, porém ainda de maneira não intencional.

${ }^{20}$ Pensamento geométrico é a compreensão de conceitos da Geometria, que segundo o modelo Van Hiele passa por cinco níveis de aprendizagem, são eles: visualização ou reconhecimento, análise, dedução informal ou ordenação, dedução formal e rigor e explicam o processo de desenvolvimento do pensamento (ALVES; SAMPAIO, 2010). 
Segundo a BNCC (BRASIL, 2017), a compreensão da criança como ser ativo, que observa, questiona, levanta hipóteses, constrói conhecimentos e se apropria do conhecimento sistematizado por meio da ação e nas interações com o mundo físico e social, não resulta de um processo de desenvolvimento natural ou espontâneo (não apenas). É importante e necessário imprimir intencionalidade educativa às práticas pedagógicas na EI. "As aprendizagens se tornam mais complexas à medida que a criança cresce, requerendo a organização das experiências e vivências em situações estruturadas de aprendizagem” (BRASIL, 2017, p. 35).

Dado o exposto, vemos ainda a necessidade de discussões sobre o ensino de Geometria em uma perspectiva mais abrangente, que não se limite ao trabalho com as figuras, principalmente no início da escolarização. Neste cenário, o livro didático surge como um recurso que pode favorecer tal ampliação, pois dependendo do tipo de abordagem presente nele, pode direcionar/orientar o professor na realização de propostas mais intencionais para o ensino de Geometria.

Compreendendo a importância do trabalho com as dimensões geométricas desde a EI e o papel do livro didático como recurso que pode favorecer este trabalho, temos como objetivo geral deste estudo investigar como está sendo abordada a Geometria em livros didáticos integrados da EI e, especificamente: identificar as atividades de Geometria presentes em livros didáticos integrados da EI e analisar os tipos e a frequência das atividades encontradas. A seguir, serão apresentadas orientações presentes em documentos curriculares nacionais acerca da EI e do ensino de Geometria na EI.

\section{O Que Dizem Os Documentos Curriculares?}

Neste tópico buscamos apresentar as orientações acerca da Matemática/Geometria nos currículos nacionais específicos para a EI ou em currículos que tenham seções que discutam sobre a temática como o Referencial Curricular Nacional para a Educação Infantil RCNEI (BRASIL, 1998), as Diretrizes Curriculares Nacionais para a Educação Infantil DCNEI (BRASIL, 2010) e a Base Nacional Comum Curricular - BNCC (BRASIL, 2017). A Matemática na EI, segundo o RCNEI (BRASIL, 1998), objetiva:

$1 \quad$ Estabelecer aproximações a algumas noções matemáticas presentes no seu cotidiano, como contagem, relações espaciais etc.;

2 Reconhecer e valorizar os números, as operações numéricas, as contagens orais e as noções espaciais como ferramentas necessárias no seu cotidiano (BRASIL, 1998, p. 215).

Além disso, o documento orienta que é tarefa da EI apresentar situações significativas que dinamizem a estruturação do espaço pelas crianças e para que adquiram 
um controle cada vez maior sobre suas ações e possam resolver problemas de natureza espacial e potencializar o desenvolvimento do seu pensamento geométrico. Portanto, o trabalho na EI deve colocar desafios que se voltem para as relações habituais das crianças com o espaço, como construir, deslocar-se, desenhar etc, e à comunicação dessas ações.

As Diretrizes Curriculares Nacionais para a Educação Infantil (BRASIL, 2010) atribuem como eixos do currículo para esta modalidade de ensino as interações e as brincadeiras, garantidas através de experiências que: 1) promovam o conhecimento de si e do mundo por meio da ampliação de experiências sensoriais, expressivas, corporais que possibilitem movimentação ampla, expressão da individualidade e respeito pelos ritmos e desejos da criança; 2) incentivem a curiosidade, a exploração, o encantamento, o questionamento, a indagação e o conhecimento das crianças em relação ao mundo físico e social, ao tempo e à natureza.

Corroborando com as orientações apresentadas pelas Diretrizes Curriculares Nacionais para a Educação Infantil, a BNCC (BRASIL, 2017), atribui como um dos direitos de aprendizagem e desenvolvimento na EI:

\begin{abstract}
Brincar de diversas formas, em diferentes espaços e tempos, com diferentes parceiros (crianças e adultos), de forma a ampliar e diversificar suas possibilidades de acesso a produções culturais. A participação e as transformações introduzidas pelas crianças nas brincadeiras devem ser valorizadas, tendo em vista o estímulo ao desenvolvimento de seus conhecimentos, sua imaginação, criatividade, experiências emocionais, corporais, sensoriais, expressivas, cognitivas, sociais e relacionais (BRASIL, 2017, p. 34 - grifo nosso).
\end{abstract}

A organização curricular da EI na BNCC é estruturada em cinco campos de experiências. Dentre eles, destacamos dois campos que se relacionam diretamente com a discussão do presente estudo. No campo Corpo, gestos e movimentos, o corpo, por meio dos sentidos, gestos e movimentos, permite à criança explorar o mundo, o espaço e os objetos do seu entorno, estabelecer relações, se expressar, brincar e produzir conhecimentos sobre si, sobre o outro, sobre o ambiente social e cultural, tornando-se, progressivamente, conscientes dessa corporeidade. "Na Educação Infantil, o corpo das crianças ganha centralidade, pois ele é o partícipe privilegiado das práticas pedagógicas [...]” (BRASIL, p. 37). Este campo objetiva aprendizagens como:

1. Explorar formas de deslocamento no espaço (pular, saltar, dançar), combinando movimentos e seguindo orientações.

2. Fazer uso de suas possibilidades corporais, ao se envolver em brincadeiras e atividades de diferentes naturezas.

3. Deslocar seu corpo no espaço, orientando-se por noções como em frente, atrás, no alto, embaixo, dentro, fora etc. (BRASIL, 2017, p. 42). 
O campo Espaços, tempos, quantidades, relações e transformações, têm conexões, dentre outros conhecimentos, com os espaços (rua, bairro, cidade) e tempos (dia e noite; hoje, ontem e amanhã) que, desde muito pequenas, as crianças procuram se situar, demonstrando interesse, sobretudo, ao mundo físico (seu próprio corpo, as transformações da natureza, os diferentes tipos de materiais e as possibilidades de sua manipulação). São aprendizagens objetivadas por este campo:

1. $\quad$ Explorar e descrever semelhanças e diferenças entre as características e propriedades dos objetos (sonoridade, textura, peso, tamanho, posição no espaço).

2. Manipular, experimentar, arrumar e explorar o espaço por meio de experiências de deslocamentos de si e dos objetos.

3. Estabelecer relações de comparação entre objetos, observando suas propriedades (BRASIL, 2017, p. 47).

Como pode ser visto nos documentos apresentados, a Geometria na EI se volta para o desenvolvimento das relações espaciais e da corporeidade da criança. Embora essas orientações sejam apresentadas desde o RCNEI (BRASIL, 1998) e reforçadas recentemente a partir da BNCC (BRASIL, 2017), a efetivação desses conhecimentos na prática da sala de aula ainda é um pouco distante. Compreender que a construção de conhecimentos matemáticos, mais especificamente das noções geométricas é intrínseca às experiências cotidianas das crianças, que se materializam em brincadeiras, interações, explorações com o mundo físico e social, é essencial para que o ensino de Geometria se volte para o trabalho com as relações espaciais no início da escolarização e progressivamente (com o avanço dos níveis), desenvolva noções mais sofisticadas que se relacionem ao trabalho amplo com as figuras.

\section{A Geometria Na Educação Básica}

Estudos como o de Ribeiro (2010), Souza e Franco (2012), Muniz (2013) vêm discutindo os conhecimentos e as práticas docentes acerca do ensino de Geometria na Educação Básica. Por meio de observações de aulas, análise de documentos oficiais, planejamentos dos professores, entrevistas semiestruturadas e relatos escritos referentes a "como" e "por que" do trabalho com Geometria.

Os pesquisadores, de um modo geral, evidenciaram tanto na prática quanto na concepção dos professores, uma Geometria que, quando trabalhada, é abordada de forma isolada dos demais campos da Matemática e normalmente centraliza-se na identificação e nomeação das figuras planas, limitada, muitas vezes, ao quadrado, triângulo, retângulo e círculo.

Muniz (2013) reflete que a função do professor não é de dar aulas ou expor conteúdos e pedir para que os alunos reproduzam o que foi ensinado. O pesquisador ressalta 
que para facilitar o aprendizado dos conteúdos matemáticos, como os geométricos, as atividades nessa faixa etária precisam envolver jogos, brincadeiras e situações-problema partindo da realidade que as crianças vivem, ao mesmo tempo em que integram as diversas áreas do conhecimento.

É consonante entre os pesquisadores supracitados a necessidade de uma melhor formação (inicial ou continuada) que lhes forneça os saberes essenciais para o desenvolvimento dos conteúdos, especificamente os conceitos matemáticos/geométricos e para a escolha de estratégias adequadas aos vários níveis de escolaridade.

Em Custódio e Nacarato (2017) é apresentada a mobilização de conceitos geométricos por alunos do $3^{\mathrm{o}}$ ano do Ensino Fundamental. Foram elaboradas e aplicadas sequências de tarefas de Geometria em parceria com a professora da turma. Neste estudo foi analisado o episódio referente aos conceitos de retângulo e paralelepípedo com o objetivo de identificar o movimento de significações, bem como a elaboração conceitual e as estratégias potencializadoras apresentadas pelos alunos.

A atividade analisada foi realizada com a turma organizada em duplas e consistia na classificação de figuras geométricas. Assim, foi entregue aos alunos uma caixa contendo diversos modelos de superfícies poliédricas e não poliédricas, uma folha com várias representações de figuras planas e espaciais e outra contendo uma tabela de classificação. Os alunos deveriam agrupar os desenhos de acordo com critérios de características comuns.

Diante dos conflitos sobre a nomeação e diferenciação das figuras (nomeando o retângulo de paralelepípedo ou "cubo esticado"), os alunos recorrem a conhecimentos já vivenciados e que são semelhantes às novas experiências. Para Custódio e Nacarato (2017), as experiências anteriores sejam no ambiente escolar, com a manipulação e a exploração de figuras espaciais e sólidos geométricos, seja nas vivências de brincadeiras e contextos sociais em que formatos de cubo e paralelepípedo estejam presentes como em caixas, dados, ou mesmo na construção civil. Este movimento ocorre porque os alunos recorrem a momentos vividos e assemelham as aprendizagens anteriores à atual.

A importância da mediação e intencionalidade docente é ressaltada pelas pesquisadoras para a produção de significados pelos alunos.

São os questionamentos que vão desestabilizando as verdades que os alunos carregam consigo, e é essa desestabilização que, promovida pela comunicação, conduz à reflexão e, consequentemente, ao desenvolvimento e à aprendizagem de novos conceitos. Nessa elaboração, é possível identificar indícios de pensamento por complexos, fase que antecede os verdadeiros conceitos no processo de elaboração conceitual, visto que os alunos estabelecem associações entre os objetos e encadeiam elaborações. Esse movimento é mediado pela palavra, que vai sendo impregnada por novas significações a cada intervenção (CUSTÓDIO; NACARATO, 2017, p. 19). 
As pesquisadoras ainda refletem que a significação dos conceitos geométricos se dá por meio da manipulação e da exploração de suas várias formas de representações. As experiências, articuladas à comunicação (que instruem, relacionam, problematizam e estabelecem relações), que se tornam material sensível à imaginação e viabilizam a criação de imagens mentais, são essenciais à constituição do pensamento geométrico.

Plaza e Curi (2017), em estudo sobre o espaço e suas relações no âmbito de um grupo de pesquisa colaborativo formado por pesquisadores e docentes dos anos iniciais, descrevem e analisam sequências de atividades produzidas pelos professores para o ensino de Geometria, focando no espaço e em suas relações.

As pesquisadoras apontam que as docentes reconhecem a importância de se proporem atividades que explorassem a posição da criança no espaço a partir de situações de aprendizagem que pudessem ser vivenciadas por ela. No entanto, apesar de explicitarem estas ideias em seus discursos, ao sugerir atividades sobre posição (localização), por exemplo, elas exploram apenas a movimentação da criança no espaço, como é observado em uma das falas das professoras "começaria com aquelas atividades de brincar, de dar o comando para o robozinho, assim: vai e dá três passos para a frente, parou. Vira para a direita e dá quatro passos, para! Eu começaria por aí” (PLAZA; CURI, 2017, p. 102-103).

Plaza e Curi (2017) afirmam que este fato pode provavelmente estar relacionado à necessidade de o professor ter clareza dos conteúdos da disciplina que vai ensinar, ou seja, mesmo identificando os conteúdos a serem trabalhados, a diferenciação entre eles frente à proposição de atividades, ainda mostra-se como desafio.

Ao serem discutidas atividades relacionadas à orientação espacial, as docentes sugerem o trabalho com base em outras referências, e não o próprio corpo da criança. "Talvez porque, em seu entendimento, o conhecimento do espaço que delimita a zona encontrada à direita ou à esquerda, a partir do próprio corpo, já fosse de domínio dos alunos" (PLAZA; CURI, 2017, p. 107). As pesquisadoras ressaltam que é preciso priorizar as atividades que privilegiem a localização tendo por referência o próprio corpo da criança, e só depois avançar com atividades que apontem outras referências, principalmente no início da escolarização.

Plaza e Curi (2017) evidenciam que ao longo das discussões e reestruturações das atividades no grupo de pesquisa, houve avanços das participantes no sentido de demonstrarem a compreensão sobre a importância do trabalho voltado para a localização espacial a partir do corpo da criança, explorando a oralidade e posteriormente a representação, por exemplo. Há, também, participantes que ainda consideravam as atividades orais e de vivência cotidiana como abstratas se comparadas àquelas encontradas em livros didáticos. 
Provavelmente porque, para essa professora, ao visualizar uma imagem ou cenário, a criança conseguiria compreender como se orientar no espaço com mais facilidade. Isso explicaria sua opção de privilegiar as atividades de representação em detrimento daquelas que investem na experimentação e exploração da vivência (PLAZA; CURI, 2017, p. 110).

Nesse contexto, podemos perceber que os avanços acontecem, mas em tempos diferentes, o que é compreensível diante das diferentes experiências de vida e profissionais de cada docente e por se tratar de uma nova perspectiva para o ensino da Geometria. Corroboramos com as pesquisadoras no sentido de que as dificuldades apresentadas pelas participantes indicam, ainda, a necessidade de maior aprofundamento e discussão sobre o conteúdo e sua prática na sala de aula.

\section{Percurso Metodológico}

Objetivamos investigar neste estudo, como está sendo abordada a Geometria em livros didáticos integrados da EI, buscando identificar e analisar os tipos e a frequência das atividades de Geometria trabalhadas neste material. Para isso, realizamos a seleção de três coleções integradas de livros didáticos da EI, compostas por três volumes cada, totalizando nove volumes destinados a crianças de três, quatro e cinco anos.

A seleção foi realizada a partir das coleções elencadas por Cruz (2013), que fez um mapeamento de coleções de livros didáticos de Matemática e integrados da EI utilizadas em trinta (30) escolas da rede particular da região metropolitana do Recife, visto que a rede pública não adota o livro didático para essa etapa de escolarização.

A escolha pelas coleções integradas se deu pelo fato de interligarem as diversas áreas do conhecimento nas atividades propostas, assim, aspectos da Geometria, tais como o trabalho com a organização do esquema corporal e orientação e percepção espaciais aparecem em outras áreas do conhecimento, além da Matemática.

$\mathrm{Na}$ análise das três coleções buscamos identificar atividades que englobassem a organização do esquema corporal, a orientação e percepção espaciais e o desenvolvimento das noções geométricas relacionadas a figuras e formas. Para isso, elencamos oito tipos de atividades que englobam essas dimensões e que serviram como categorias para análises dos resultados.

Essa tipologia foi definida por nós, embasadas por estudos como os de Piaget e Inhelder (1993), Cerquetti-aberkane e Berdonneau (1997), Smole, Diniz e Cândido (2003) e Aguiar (2006) que discutem o trabalho com Matemática/Geometria na EI. No Quadro 1, a seguir, apresentamos as categorias de atividades e a sua descrição. 
Quadro 1: Categorias de atividades de Geometria

\begin{tabular}{|c|c|}
\hline $\begin{array}{l}\text { Categorias de } \\
\text { atividades }\end{array}$ & Descrição \\
\hline $\begin{array}{l}\text { Organização do } \\
\text { esquema } \\
\text { corporal }\end{array}$ & $\begin{array}{l}\text { São atividades em que a criança pode tomar consciência de seu corpo, estatura, posições } \\
\text { de seus membros, lados do seu corpo. Exemplos, brincadeiras de bola, corda, amarelinha, } \\
\text { construção de moldes do corpo etc. }\end{array}$ \\
\hline $\begin{array}{l}\text { Localização } \\
\text { espacial }\end{array}$ & $\begin{array}{l}\text { São atividades em que a criança deverá localizar-se e localizar objetos em meio a outros } \\
\text { objetos e pessoas em determinado espaço. Possui sentido estático. Exemplo: localizar } \\
\text { objetos em cima, embaixo, à esquerda ou à direita de algo, representar sua posição na sala } \\
\text { de aula ou em outro ambiente. }\end{array}$ \\
\hline $\begin{array}{l}\text { Orientação } \\
\text { espacial }\end{array}$ & $\begin{array}{l}\text { São atividades em que a criança precisa orientar-se no espaço e, para isso, geralmente são } \\
\text { utilizados pontos de referências conhecidos pelas mesmas. São atividades dinâmicas e que } \\
\text { exigirão da criança perceber caminhos, relações que ela fez para chegar a determinado } \\
\text { lugar. Tem um sentido dinâmico, explorando direção e movimento. Exemplo: quando é } \\
\text { perguntado para a criança: Como se pode chegar a determinado lugar? Que caminho } \\
\text { seguir? Como cheguei? }\end{array}$ \\
\hline $\begin{array}{l}\text { Representação } \\
\text { espacial }\end{array}$ & $\begin{array}{l}\text { São atividades que possibilitam à criança expressar em forma de registro sua percepção } \\
\text { do espaço; expressar aquilo que a criança já internaliza sem, necessariamente, estar em } \\
\text { seu campo de visão. Exemplos: os desenhos de figuras e espaços concebidos pelos alunos, } \\
\text { plantas, trajetos, mapas, maquetes etc. }\end{array}$ \\
\hline $\begin{array}{l}\text { Figuras } \\
\text { bidimensionais }\end{array}$ & $\begin{array}{l}\text { São aquelas que envolvem o trabalho de identificar, comparar, descrever, desenhar, } \\
\text { classificar formas geométricas planas. Exemplos: compor e decompor figuras a partir do } \\
\text { Tangram, classificar por tamanho e forma quadrados, triângulos, retângulos, trapézios } \\
\text { etc. Nestas atividades podem ser utilizados recursos como: Blocos Lógicos, Tangram, } \\
\text { dobraduras etc. }\end{array}$ \\
\hline $\begin{array}{l}\text { Figuras } \\
\text { tridimensionais }\end{array}$ & $\begin{array}{l}\text { São as que envolvem identificação, nomeação, comparação, representação e } \\
\text { reconhecimento das características de sólidos geométricos como cone, cilindro, } \\
\text { paralelepípedo, cubo, esfera, entre outros. Exemplos: planificação de sólidos, situações de } \\
\text { manuseio e exploração de materiais do cotidiano como caixas de formatos diversos, bolas, } \\
\text { latas, entre outros, para compreensão de características dos sólidos e relação existentes } \\
\text { com as figuras planas. }\end{array}$ \\
\hline $\begin{array}{l}\text { Transformações } \\
\text { no plano } \\
\text { bidimensional }\end{array}$ & $\begin{array}{l}\text { São as que envolvem simetria, reduções e ampliações no plano, atividades nas quais há } \\
\text { mudanças no plano bidimensional. Exemplo: Redução e ampliação de figuras planas em } \\
\text { malhas; construção de figuras a partir de um eixo de simetria. }\end{array}$ \\
\hline Outros & $\begin{array}{l}\text { São atividades que envolvem identificação e representação de pontos de vista e figuras } \\
\text { unidimensionais, percepção e exploração de formas no espaço através de jogos para } \\
\text { encontrar figuras iguais e diferentes (exemplo: sete erros), composição e decomposição de } \\
\text { formas e organização do espaço a partir de quebra-cabeças. Exemplos: desenhar objetos } \\
\text { em posições diferentes (de cima, de baixo, de lado), construir figuras utilizando linhas } \\
\text { retas e/ou curvas, identificar diferenças em duas imagens iguais, montar/produzir } \\
\text { quebra-cabeças. }\end{array}$ \\
\hline
\end{tabular}


No próximo tópico discutiremos os resultados encontrados na coleta realizada nos livros integrados da EI.

\section{Resultados E Discussões}

Identificamos nas três coleções analisadas 287 atividades de Geometria. Percebemos uma grande diferença em relação à quantidade de atividades apresentadas entre as coleções, na Coleção $C^{21}$ encontramos cento e trinta e sete (137) atividades, seguida pela Coleção B, com noventa (90) atividades e pela Coleção A, com sessenta (60) atividades. Destas duzentas e oitenta e sete (287) atividades de Geometria, podemos identificar cento e cinquenta e três (153) explicitadas na área de Matemática e cento e trinta quatro (134) explicitadas em outras áreas do conhecimento como corpo e movimento, natureza e sociedade, conhecimento de mundo etc. Salientamos que dentre estas cento e cinquenta e três (153) atividades da área de Matemática há também a relação com outros eixos, visto que é um aspecto das coleções integradas o trabalho envolvendo mais de um eixo de aprendizagem nas atividades.

No Gráfico 1 a seguir, será apresentada a frequência destas atividades de Geometria por volume.

Gráfico 1: Frequência de atividades de Geometria por volume nas coleções

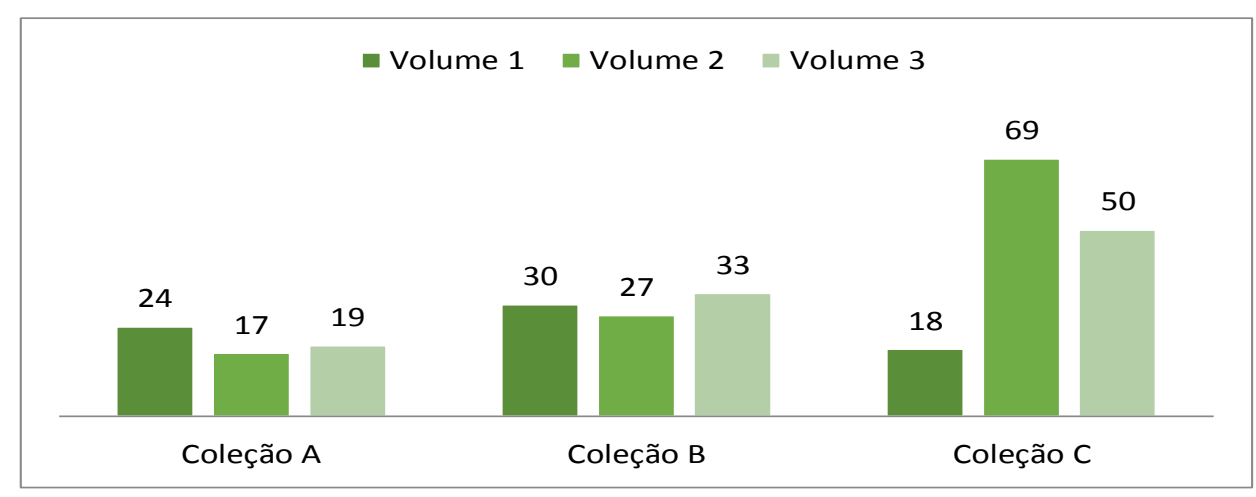

Fonte: As autoras.

Ao observar o Gráfico 1, o qual considera a frequência das atividades de Geometria por volume, verificamos uma predominância nos volumes 1 e 3 das coleções A e B, em relação ao Volume 2. Contudo, na Coleção C, o Volume 2 é o que mais apresenta atividades, 
ultrapassando todos os outros volumes. Podemos perceber que não há uma linearidade, nem uma progressão do quantitativo das atividades a cada volume.

\section{Tipos e frequência das atividades de Geometria}

Neste tópico apresentaremos a frequência e as análises dos tipos de atividades identificadas nas coleções. Constatamos que todas as atividades que englobam as dimensões do campo geométrico foram contempladas nas coleções analisadas.

Ao analisarmos a frequência por tipo de atividade nas coleções, identificamos a predominância das que envolvem a organização do esquema corporal, com noventa e oito (98) atividades (34\%), seguida por cinquenta e três (53) atividades com figuras bidimensionais (18,5\%), e quarenta e um (41) atividades de representação espacial (14\%). Os demais tipos de atividades foram trabalhados com menor frequência, como as de localização espacial, com trinta (30) atividades (10,5\%); as de orientação espacial, com vinte e um (21) atividades (7,5\%); as de transformações no plano bidimensional, com dez (10) atividades (3,5\%); e as figuras tridimensionais (sólidos geométricos), com apenas sete (7) atividades $(2,5 \%)$ das encontradas nas três coleções.

A categoria outros, constituída por atividades de ponto de vista, figuras unidimensionais, quebra-cabeça e jogos de iguais ou diferentes, representa 9,5\%, com vinte e sete (27) atividades. Consideramos a predominância da organização do esquema corporal como um aspecto positivo do trabalho com a Geometria, pois, de acordo com o referencial adotado neste estudo (Cerquetti-Aberkane e Berdonneau (1997), Smole; Diniz e Cândido (2003)), a organização do esquema corporal favorece uma posterior organização/percepção espacial.

A predominância de atividades de organização do esquema corporal ocorre porque estas são trabalhadas não apenas em Geometria, mas em outras áreas do conhecimento, sobretudo, em Ciências, o que aumenta a sua frequência. A Tabela 1, a seguir, sintetiza numericamente as afirmativas acima.

Tabela 1: Frequência dos tipos de atividades por volume nas coleções

\begin{tabular}{lllll}
\hline Coleção & Coleção & Coleção & Total \\
A & B & C & \\
\hline
\end{tabular}




\begin{tabular}{|c|c|c|c|c|c|c|c|c|c|c|}
\hline Tipos de atividades & $V .1$ & $V .2$ & $V .3$ & $V .1$ & $V .2$ & $V \cdot 3$ & $V .1$ & $V .2$ & $V .3$ & \\
\hline $\begin{array}{l}\text { Organização do esquema } \\
\text { corporal }\end{array}$ & 11 & 07 & 09 & 06 & 05 & 02 & 08 & 29 & 21 & 98 \\
\hline Figuras bidimensionais & 06 & 03 & 03 & 11 & 05 & 11 & 02 & 03 & 09 & 53 \\
\hline Representação do espaço & $\mathrm{O} 2$ & - & - & 01 & 04 & $\mathrm{O} 2$ & 04 & 21 & 07 & 41 \\
\hline Localização espacial & 02 & 04 & 03 & 05 & 05 & 05 & - & 03 & 03 & 30 \\
\hline Outros & 02 & 02 & - & 03 & 02 & 06 & 02 & 09 & 02 & 27 \\
\hline Orientação espacial & 01 & 01 & 02 & 03 & 04 & 03 & 02 & - & 05 & 21 \\
\hline $\begin{array}{l}\text { Transformações no plano } \\
\text { bidimensional }\end{array}$ & - & 01 & 01 & - & - & 02 & - & 03 & 03 & 10 \\
\hline Figuras tridimensionais & - & - & 01 & 01 & 02 & 02 & - & 01 & - & 07 \\
\hline Total & 24 & 18 & 19 & 30 & 27 & 33 & 18 & 69 & 50 & 287 \\
\hline
\end{tabular}

Fonte: As autoras.

Analisando a frequência dos tipos de atividades por volumes representados na Tabela 1, concluímos que ainda é preciso haver uma ampliação das atividades envolvendo a orientação, a localização e a representação espaciais, visto que são pouco abordadas e por serem essenciais para a construção da competência espacial. A seguir, fazemos uma análise qualitativa de cada tipo de atividade trabalhada nas coleções.

\section{Organização do esquema corporal}

Verificamos que todas as coleções, trabalham a organização do esquema corporal. Esta dimensão é explorada por meio de brincadeiras, jogos, cantigas de roda, sequências. É proposta para os alunos a vivência de brincadeiras que possibilitam desenvolver habilidades motoras, cognitivas e sociais, oportunizando reconhecer, delimitar e organizar o espaço, desenvolver a lateralidade, trabalhar o reconhecimento corporal, realizar movimentos etc. Exemplos: amarelinha, pula corda, rodas com cantigas.

O trabalho com brincadeiras desenvolvido nas coleções analisadas, além de constituir-se como um eixo do currículo segundo as Diretrizes Curriculares Nacionais para a Educação Infantil (BRASIL, 2010) está em consonância com as orientações explicitadas no RCNEI (BRASIL, 1998, p.15) o qual afirma que, "ao brincar, jogar, imitar e criar ritmos e movimentos, as crianças também se apropriam do repertório da cultura corporal na qual estão inseridas".

As atividades de organização do esquema corporal são trabalhadas, em sua maioria, em outros eixos de aprendizagem, diferente do matemático. Quando não há uma relação explícita entre a atividade e a área a ela relacionada, muitas vezes dificulta a ampliação da atividade de forma intencional, limitando a mesma. Essas limitações das atividades se 
refletem na prática do professor, pois embora estudos e documentos da área indiquem a importância de se trabalhar o corpo e o espaço, além das figuras e formas na Geometria, na prática, de acordo com Silva, Silva e Pessoa (2014), esse eixo vem continuamente se restringindo ao ensino de figuras e formas. Acreditamos que isto ocorra por essas serem explicitadas como atividades de Matemática/Geometria, em detrimento das atividades que envolvem o corpo e o espaço, por exemplo. A Figura 1, apresentada abaixo, exemplifica uma das atividades referidas acima.

Figura 1: Atividade de organização do esquema corporal

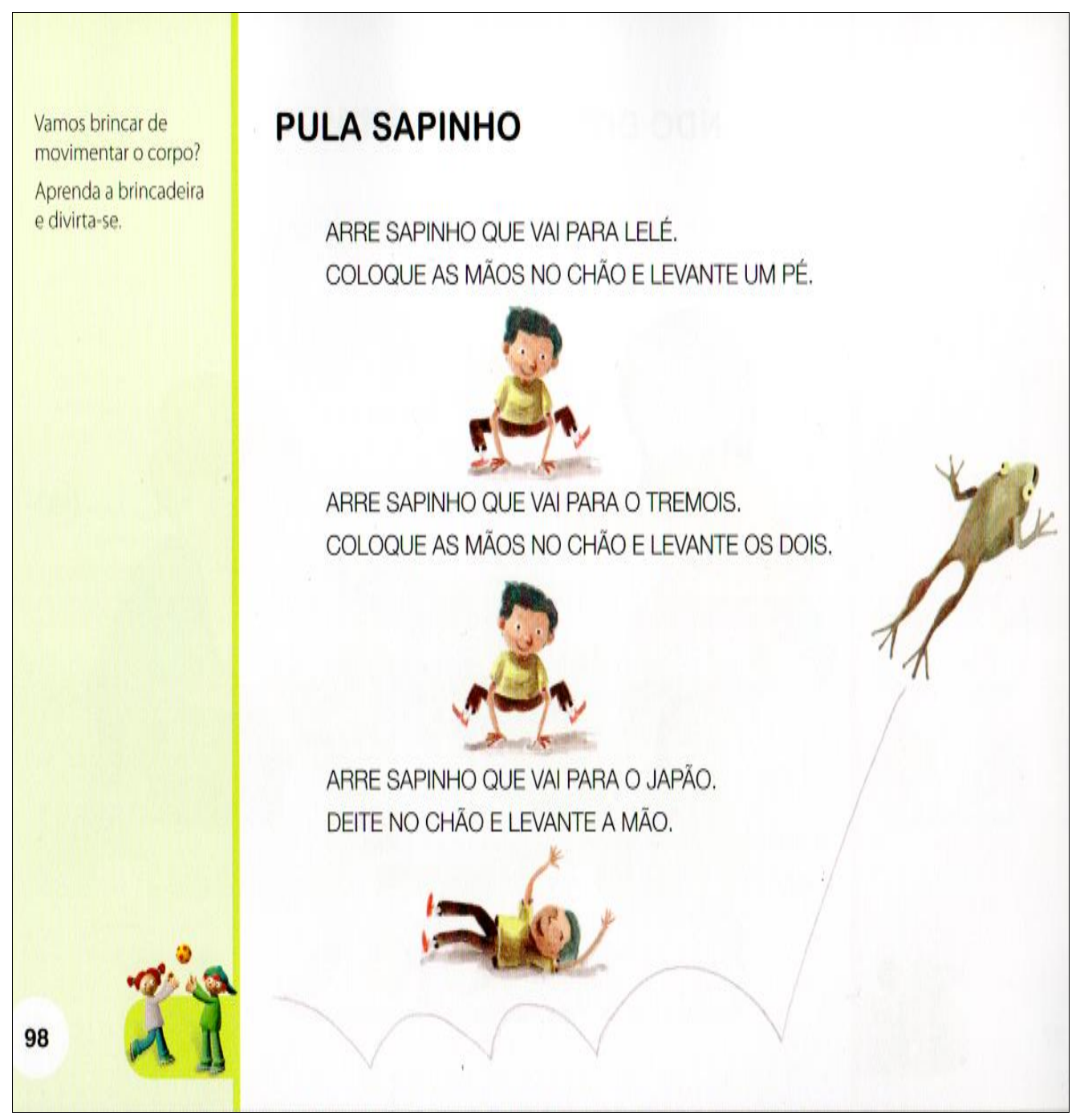

Fonte: Moderna V.1, 2010, p. 98.

Nesta atividade, indicada no eixo corpo e movimento, é proposta uma brincadeira com rimas relacionadas às partes do corpo, na qual, a criança precisará desenvolver movimentos e deslocamentos correspondentes aos comandos. As orientações da atividade sugerem que o professor e/ou aluno inventem outras rimas e outras posições do corpo. Esta 
atividade, além de favorecer a identificação e percepção das partes do corpo, também possibilita o trabalho com a lateralidade, exploração do espaço, equilíbrio e atenção aos comandos.

Identificamos entre as unidades da Coleção A, seções de jogos e brincadeiras. Nesta coleção encontramos treze (13) seções, nas quais são propostos vinte e sete (27) tipos de jogos e brincadeiras, todos voltados para o trabalho com corpo, movimento, posição, percepções de espaços, equilíbrio, interação e cooperação na superação de desafios presentes nas brincadeiras. Exemplos: cordas (vários tipos), amarelinha, cada macaco no seu galho, etc. Em cada seção são discriminados a faixa etária, os objetivos, espaço e recursos necessários, papéis no jogo, organização e dicas de ampliação do jogo. Verificamos nas atividades de organização do esquema corporal um trabalho lúdico e diversificado, no qual o corpo é o instrumento da ação, e que, por isso, nas coleções são oportunizadas brincadeiras e atividades que favorecem conversar, explorar e identificar as partes e lados do corpo, entretanto, observamos que o incentivo ao registro ainda é escasso. O registro da criança ajuda o professor a acompanhar e avaliar o processo de desenvolvimento e de compreensão dos seus alunos. Segundo o RCNEI (BRASIL, 1998, p. 237) "a avaliação representa, neste caso, um esforço do professor em observar e compreender o que as crianças fazem e os significados atribuídos por elas aos elementos trabalhados nas situações vivenciadas".

\section{Orientação espacial}

As atividades referentes à orientação espacial se constituem em trabalho com direção e sentido, exploração e representação espacial a partir de referências. É trabalhada nas coleções através de noções de caminho (curto, longo, largo, estreito), brincadeira com comandos de direção, mapas do tesouro, situação-problema, a qual a criança precisa pensar e informar referencial para o estabelecimento de direção e sentido do deslocamento. Para o RCNEI (BRASIL, 1998): As relações espaciais entre os objetos envolvem noções de orientação, como proximidade, interioridade e direcionalidade. Para determinar a posição de uma pessoa ou de um objeto no espaço é preciso situá-los em relação a uma referência, seja ela outros objetos, pessoas etc. (BRASIL, 1998, p. 230).

Consideramos importante o trabalho com atividades de orientação, pois ela possibilita que a criança vá desprendendo-se de seu egocentrismo espacial, ao qual só toma a si como referência, e vá aos poucos descentralizando-se, ampliando a observação para os objetos ao seu redor. A Figura 2 a seguir, representa uma dessas atividades.

Figura 2: Atividade de orientação espacial 


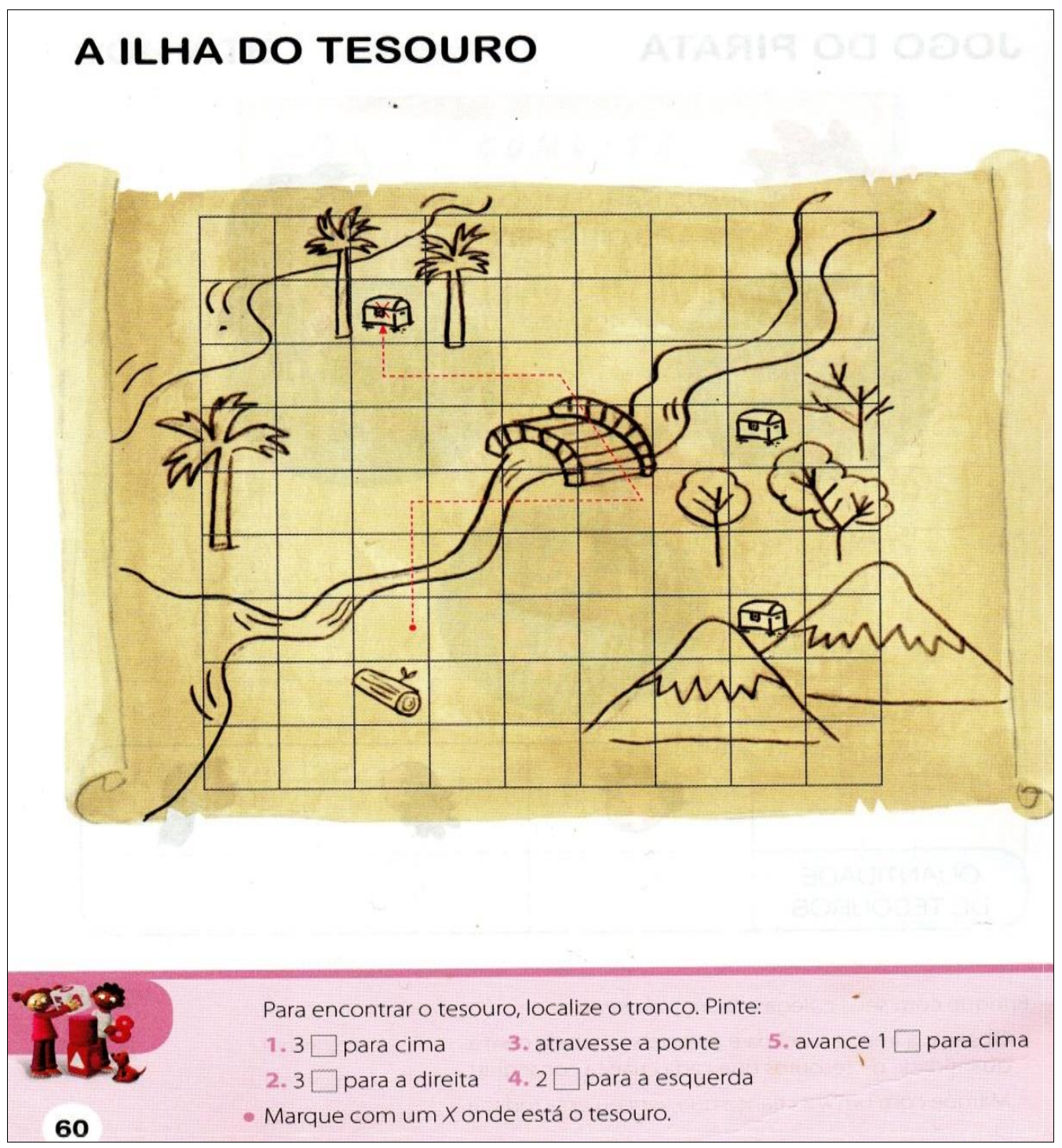

Fonte: Moderna, V.3, 2010, p.6o.

Nesta atividade a criança terá que executar orientações referentes ao direcionamento que deverá realizar (seguir alguns quadrados para cima, para a esquerda, para a direita, seguir em frente). Essa atividade, além de favorecer a identificação de pontos de referência para situar-se, deslocar-se no espaço, faz uso do vocabulário adequado à orientação. Nesta atividade também identificamos o trabalho com a localização espacial (localizar tesouro). Por fazerem parte do mesmo campo conceitual (o do espaço), orientação e localização espaciais, encontram-se geralmente atreladas nas atividades, pois “...a noção de referencial é básica em todas as atividades que envolvem localização e movimento" (LIMA; CARVALHO, 2010, p. 149). Torna-se imprescindível, de acordo com o objetivo de ensino definido pelo professor, no caso de atividade de orientação, destacar os referenciais presentes, pois do contrário, perde o sentido da orientação, sendo apenas destacada a localização. 
As atividades de orientação espacial identificadas nas coleções exploram bastante a noções de caminhos, enfatizando os deslocamentos, entretanto este trabalho é realizado de forma bem elementar, não oportunizando desafios, explorando pouco os aspectos relacionados a pontos de referência e lateralidade, por exemplo. Aguiar (2006) afirma que a construção do conceito de orientação espacial envolve noções de direção dos deslocamentos (horizontal, vertical etc), sentidos dos deslocamentos (para frente, para trás, para a direita, para a esquerda), referencial para o estabelecimento de direção e sentido dos deslocamentos, comparação entre as direções e sentidos de deslocamentos, envolvendo sistemas de coordenadas.

\section{Localização espacial}

As atividades de localização são apresentadas nas coleções, em sua maioria por desafios, nos quais são fornecidas dicas para facilitar a localização. É trabalhada a localização de pessoas, objetos e lugares, a partir de mapas, desenhos, globo terrestre e desafios, como já referido. Mesmo sendo um dos conteúdos explicitados nas orientações presentes no RCNEI (BRASIL, 1998, p. 229) "explicitação e/ou representação da posição de pessoas e objetos, utilizando vocabulário pertinente nos jogos, nas brincadeiras e nas diversas situações nas quais as crianças considerarem necessária essa ação", o trabalho com a localização ainda aparece muito pouco nas coleções. Considerando os dados obtidos, vemos que as coleções A e B trabalham em todos os volumes a localização, a Coleção C só o faz nos volumes 2 e 3 , apresentando a mesma quantidade de atividades em seus dois volumes.

Nas atividades de localização, identificamos o trabalho com noções de proximidade e o uso de referencial para o estabelecimento das posições e organização dos objetos no espaço, aspectos positivos de serem trabalhados e que atribuem qualidade às atividades. Contudo, não há nas atividades que envolvem o trabalho com a comparação entre as posições de objetos, envolvendo coordenadas, por exemplo.

Segundo Lima e Carvalho (2010): Reconhecer se um objeto ou uma pessoa está longe ou perto, em cima ou embaixo, à direita ou à esquerda, requer que se estabeleça sempre outro objeto ou pessoa como referência: longe ou perto da casa de Maria; em cima ou embaixo da mesa; à direita ou à esquerda de Pedro (LIMA; CARVALHO, 2010, p. 149). A seguir, na Figura 3, trazemos um exemplo de atividade de localização.

Figura 3: Atividade de localização espacial 


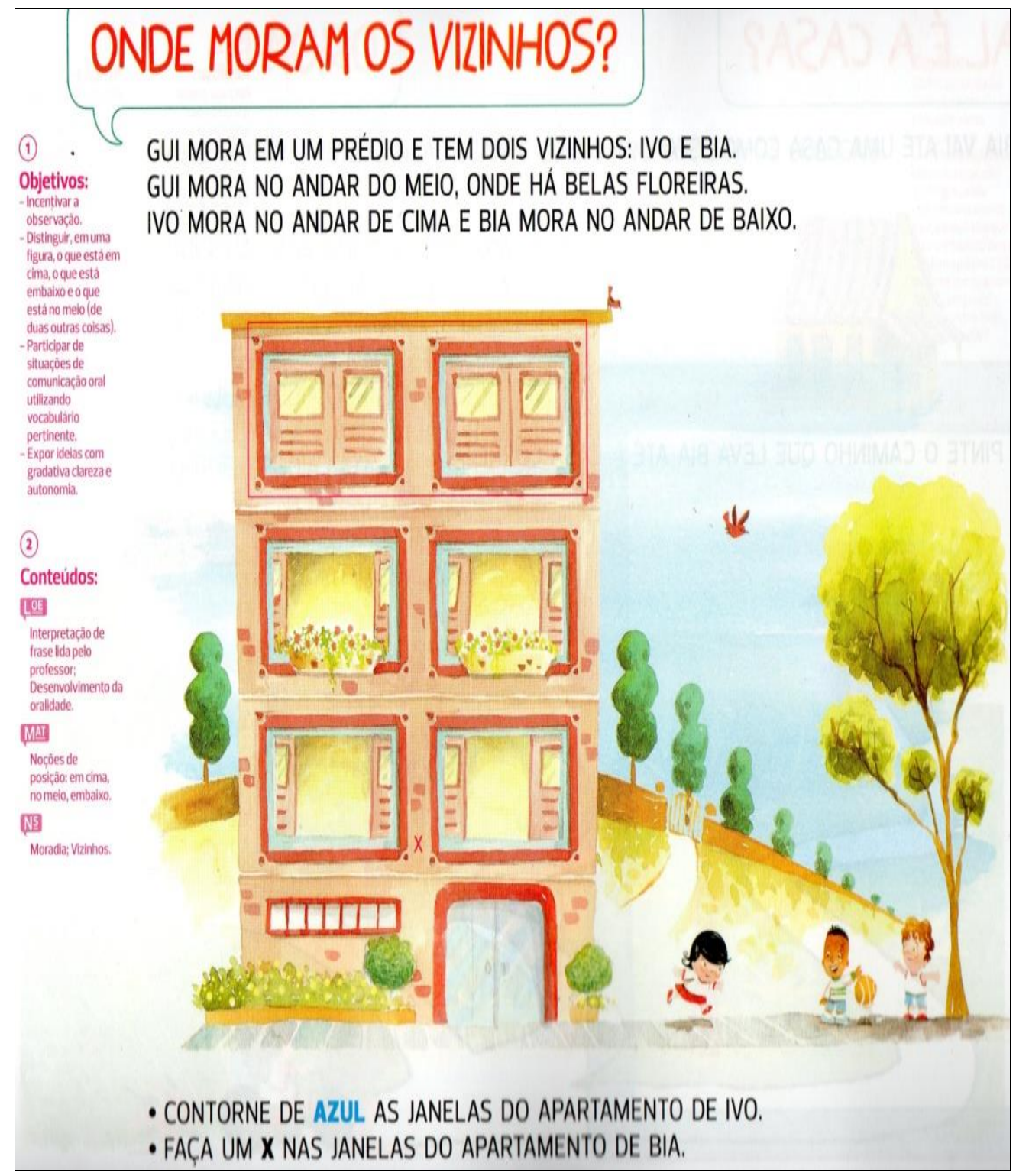

Fonte: Dante e Bianchini. V.1, 2013, p.68.

Nesta atividade a criança terá que localizar espaços (apartamentos), tomando como referência outro espaço, utilizando algumas orientações de posição como em cima, embaixo, no meio e utilizando estratégias de eliminação de alternativas. Esta atividade, além de oportunizar a estabilidades de relações espaciais, permite à criança orientar-se no espaço próximo e localizar um ou mais objetos com relação entre eles e a quem observa, favorecendo assim, a percepção espacial.

\section{Representação do espaço}

Referente à representação do espaço, identificamos nas coleções, atividades que envolvem a representação de ruas, escola, casa, representação de brincadeiras e seus circuitos vivenciados no espaço escolar e construção de maquetes. De acordo com o RCNEI (BRASIL, ISSN 2526-2882 
1998, p. 229) "cada criança constrói um modo particular de conceber o espaço por meio das suas percepções, do contato com a realidade e das soluções que encontra para os problemas”. Piaget e Inhelder (1993) afirmam que a falta de exploração do espaço explica também as dificuldades de desenho/representação.

Constatamos que tanto a Coleção A quanto a Coleção B, trabalharam muito pouco este tipo de atividade, diferentemente da Coleção $\mathrm{C}$, que após várias atividades, geralmente com brincadeiras, pede um registro representativo por meio de desenhos, colagens ou maquete e, como discutido anteriormente, o registro auxilia o professor na avaliação dos alunos. Por exemplo, são realizadas na aula brincadeiras com roda, bola, imitação, e depois é solicitado para que o aluno represente por desenhos como foi vivenciada tal brincadeira. Consideramos boas as atividades apresentadas nas coleções, pois esta relação de exploração do meio físico e posterior representação auxilia na consolidação da percepção/organização e representação destes espaços pela criança. Sobre isso, Smole, Diniz e Cândido (2003) afirmam a importância dos desenhos, pois os mesmos favorecem a construção e a evolução da percepção do espaço ao redor da criança e de sua representação. Segundo o RCNEI (BRASIL, 1998, p. 232) "para coordenar as informações que percebem do espaço, as crianças precisam ter oportunidades de observá-las, descrevê-las e representá-las”.

Entretanto, observamos que mesmo as coleções contendo um grande quantitativo de atividades que exploram e representam o espaço (predominantemente na Coleção C), em relação à variedade dos tipos de atividades, elas se limitam à exploração de desenho de pessoas/objetos e maquete para a representação da percepção espacial da criança, não explorando em nenhum momento a representação em plantas, trajetos ou mapas. Essa limitação dos tipos de representação (a apenas dois) empobrece um pouco o trabalho deste conceito geométrico nas atividades identificadas, pois restringe o desenvolvimento de noções de tamanho, de lateralidade, de localização, de direcionamento, de sentido e de vistas. Para Lima e Carvalho (2010, p.150) "outra tarefa importante no ensino escolar é levar a criança a adquirir competências mais elaboradas de localização de objetos e de observação de deslocamentos deles, com o apoio de representações gráficas como os croquis, as plantas e os mapas".

\section{Figuras bidimensionais}

As figuras planas/bidimensionais se apresentam nas coleções partindo do reconhecimento, identificação, construção de figuras planas e comparação dessas figuras com objetos do cotidiano da criança, objetos tridimensionais. Exemplos: atividades de nomeação de figuras planas e classificação de algumas características (lados, vértices), Tangram, dobraduras, sequências, etc. De acordo com o RCNEI (BRASIL, 1998, p. 230) "As relações 
espaciais contidas nos objetos podem ser percebidas pelas crianças por meio do contato e da manipulação deles. A observação de características e propriedades dos objetos possibilita a identificação de atributos como quantidade, tamanho e forma”.

Esse tipo de atividade, juntamente com os sólidos geométricos é explicitado como conteúdos de Matemática, dentre eles, alguns no eixo Espaço e Forma/Geometria. Isso mostra que, mesmo ao trabalhar todas as dimensões abordadas neste estudo, as coleções analisadas, identificam como conteúdos para ensino de Geometria em sua maioria, o trabalho com figura e formas, incluindo pouquíssimas atividades de outras dimensões neste eixo, quando trabalhado explícita e formalmente.

As figuras planas, de um modo geral, são apresentadas em diferentes posições, o que é positivo, pois habitua o aluno a perceber que os triângulos, por exemplo, são mais do que aqueles prototípicos que são tradicionalmente apresentados. Os triângulos se diferem tanto na posição, quanto ao tipo (escaleno, isósceles e equilátero).

Isso mostra a preocupação em oportunizar a visualização da figura em diferentes posições e tipos, favorecendo a ampliação da percepção das formas independente de sua variabilidade de representação visual. Cerquetti-Aberkane e Berdonneau (1997, p.139) corroboram dizendo que "se a criança lida, por exemplo, somente com triângulos equiláteros, a noção de triângulo não poderá ser construída corretamente, pois será a igualdade dos comprimentos dos lados que prevalecerá”.

Embora as coleções trabalhem com diversos recursos e perspectivas de representação, estimulem a relação das figuras com objetos do cotidiano (figuras tridimensionais), oportunizem a construção de figuras a partir das formas e possibilitem a classificação destas formas de acordo com os seus atributos definidores, suas características (lados, ângulos) e também a partir de atributos irrelevantes (cor, tamanho, posição), constatamos que as mesmas desenvolvem todo o trabalho com figuras planas, partindo apenas de figuras como quadrado, triângulo, retângulo e círculo, com exceção de apenas duas atividades.

Por exemplo, na Coleção $\mathrm{C}$, volume 3, foi identificada uma atividade que oportuniza o trabalho com o Tangram (que além do triângulo e quadrado, contempla também o paralelogramo em suas peças), é pedido, após exploração das peças (quantas peças, quais os nomes, semelhanças de formas e tamanho), que montem a figura de um barco. Esta restrição de formas abordadas limita o estabelecimento de relações sobre conceitos e a realização de classificações. 


\section{Transformações no plano bidimensional}

O trabalho com as transformações no plano bidimensional foi abordado nas coleções, por atividades de simetria e pelo trabalho intuitivo de ampliação de figuras no plano. Identificamos atividades de complemento de simetria em malhas quadriculadas, construção de mosaicos, ampliação de figuras em malhas quadriculadas.

O uso da malha é um facilitador, principalmente no trabalho com as crianças pequenas, porque elas podem utilizar a contagem, posição do quadradinho para realizar o complemento ou ampliação da figura de forma semelhante, proporcional.

Este tipo de atividade foi identificado nos volumes 2 e 3 das coleções A e C e apenas no volume 3 da Coleção B. Atribuímos essa ausência das atividades nos primeiros volumes das coleções, por haver uma maior complexidade presente nas atividades pois, para resolvêlas, a criança precisará mobilizar conhecimentos/habilidades referentes à proporcionalidade, constância de forma e tamanho e percepção de posição, conhecimentos estes, mais complexos para alunos da EI.

Segundo o RCNEI (BRASIL, 1998) o trabalho com figuras geométricas também pode ser realizado a partir de observação de obras de arte, construções de pisos, mosaicos, vitrais, por formas encontradas na natureza, em folhas, flores, etc. Esta variedade de atividades que podem ser desenvolvidas a partir das transformações no plano enriquece ainda mais o trabalho com a Geometria, pois favorece a relação da forma real, ao ser construída/representada no plano e as mudanças/transformações que são possíveis de realizar a partir dele, como ampliações, reduções de formas proporcionais ou iguais, no caso das simetrias de reflexão que são trabalhadas nas coleções.

Apesar de ser pouco abordado nas coleções (em apenas 10 atividades) o trabalho com as transformações ocorre de forma adequada em relação à faixa etária. Por exemplo, a simetria apresentada é a de reflexão, a qual possui como característica a relação a uma reta, quando podem ser superpostas exatamente com uma única dobra ao longo dessa reta, e que possui um eixo que divide uma figura em duas partes iguais.

Smole, Diniz e Cândido (2003) afirmam ser esse tipo de simetria mais fácil de ser identificada pelas crianças, pois ela se direciona a habilidades espaciais desenvolvidas nesta faixa etária, como discriminação visual, percepção de posição e constância de forma e tamanho. Este trabalho poderia ser ampliado se, além do complemento de figuras e construção de borrões simétricos, fossem trabalhadas também simetrias a partir de construção de objetos, recortes, simetrias relacionadas às formas geométricas. 


\section{Figuras tridimensionais (sólidos geométricos)}

As coleções abordam os sólidos geométricos partindo de atividades de identificação, comparação e nomeação dos sólidos, sua relação com objetos do cotidiano e exploração de algumas características (faces, aresta, vértices). Por exemplo: relacionem os sólidos (cone, cilindro, esfera, cubo) às figuras presentes na imagem (contexto de festa de aniversário), explorem os objetos presentes na sala, comparando aos sólidos estudados, pintem da mesma cor as figuras que se parecem etc.

As atividades com sólidos geométricos foram as menos trabalhadas nas coleções, porque há muitos anos convencionou-se no ensino de Geometria que, primeiro se trabalham as figuras planas (segunda categoria mais trabalhada nas coleções) para posteriormente trabalhar com os sólidos, embora o RCNEI (BRASIL, 1998, p. 229) oriente para que sejam trabalhados, explicitando nos conteúdos do eixo Espaço e Forma/Geometria a "exploração e identificação de propriedades geométricas de objetos e figuras, como formas, tipos de contornos, bidimensionalidade, tridimensionalidade, faces planas, lados retos etc.”. Sabendo que a criança constrói suas primeiras noções geométricas a partir das explorações feitas no espaço e por serem os sólidos mais próximos aos objetos reais do cotidiano, seria mais positivo e significativo um trabalho conjunto entre as figuras bidimensionais e tridimensionais. Para Lima e Carvalho (2006):

Na formação geométrica inicial, devemos fazer uma abordagem integrada e simultânea das figuras geométricas de várias dimensões, em contraposição ao que se recomendou, durante algum tempo, que era partir das figuras unidimensionais, seguidas das bidimensionais e, depois, das tridimensionais (LIMA; CARVALHO, 2010, p. 141).

Smole, Diniz e Cândido (2003) afirmam que "enquanto manipula, constrói e representa objetos tridimensionais, [...] a criança descobre formas, percebe dimensões, observa semelhanças e diferenças, desenvolve noções e perspectivas” (p. 131).

Constatamos nas coleções o trabalho com os sólidos voltado apenas para a identificação e manuseio de blocos de montar e identificação das figuras em imagens (como já exemplificado acima). Entretanto, faz-se necessário também o desenvolvimento de atividades de experimentação, as quais não foram propostas em nenhuma das coleções.

Essa experimentação pode partir de atividades com construção de sólidos com massinha de modelar, com palitos ou canudos, com planificações. Este trabalho permite à criança criar hipóteses antes das construções e validá-las ou não após construção ou planificação, ajudar a relacionar as faces dos sólidos com figuras planas, estabelecendo assim, relações com o espaço físico e geométrico. 


\section{Categoria Outros}

As atividades consideradas nesta categoria são referentes a pontos de vista, figuras unidimensionais, jogo para encontrar figuras iguais e diferentes e quebra-cabeças. Trabalhadas nas coleções por meio de atividades de identificação e percepção de formas no ambiente; representação e identificação de desenhos a partir de diferentes perspectivas; observação, identificação e análises de construções formadas por linhas retas e curvas; quebra-cabeça de espaços e objetos e jogos de sete erros.

Referente às atividades sobre ponto de vista, o RCNEI (BRASIL, 1998, p. 32) afirma que "desenhar objetos a partir de diferentes ângulos de visão, como visto de cima, de baixo, de lado, e propor situações que propiciem a troca de ideias sobre as representações é uma forma de se trabalhar a percepção do espaço". Atividades deste tipo favorecem também a percepção de formas em meio a estímulos visuais, bem como a sensibilização do olhar para as especificidades/características da forma e objetos presentes no espaço.

A abordagem deste tipo de atividade em livros de EI é um aspecto bastante positivo, embora a habilidade de descentralizar a visão de objetos para outros pontos de vista, diferentes do seu, não seja adquirido nesta faixa etária, segundo estudos de Piaget e Inhelder (1993) sobre a percepção e representação espacial, focando o relacionamento das perspectivas. Piaget e Inhelder (1993) afirmam que mesmo adquirindo nos primeiros anos a constância de formas perceptivas e representativas de grandes objetos (como edifícios, montanhas), a criança não consegue ainda utilizar essa constância no caso de muitos objetos reunidos em uma estrutura, recorrendo sempre ao seu próprio ponto de vista, considerandoo como absoluto.

As atividades de quebra-cabeça oportunizam a visualização e reconhecimento de formas, análises de características, composição e decomposição de figuras, bem como a delimitação e organização do espaço, percepção de posição e distância (SMOLE, DINIZ; CÂNDIDO, 2003). No campo matemático, mais especificamente na Geometria, o quebracabeça favorece habilidades constituintes da percepção espacial, como discriminação visual e habilidade visuomotora. Referente às formas geométricas, amplia o trabalho com figuras, sua identificação e percepção de figuras planas, limites no espaço e a compreensão de semelhanças entre as formas e de sua variabilidade de impressões, além de, na maioria dos casos, não utilizar formas prototípicas, tais como triângulo, quadrado, retângulo, por exemplo.

Atividades que trabalham com a visualização e a discriminação das formas no espaço, como os jogos de iguais e diferentes, identificados nas coleções, possibilitam "de um lado, captar e interpretar as informações provenientes do mundo que nos cerca e que são 
mediadas pela visão humana, bem como constituir imagens mentais e ideias baseadas nessas informações" (LIMA; CARVALHO, 2010, p. 144).

Outro tipo de atividade abordada nesta categoria é com figuras unidimensionais, trabalhadas na coleção a partir de linhas retas e curvas, buscando sua identificação, nomeação e utilização em representação de espaços. Sobre as dimensões unidimensionais, Lima e Carvalho (2010), apontam que:

As "quinas" das paredes em nossas casas, as arestas de uma caixa de sapatos são exemplos concretos de figuras geométricas unidimensionais, os segmentos de reta. Já o contorno de um CD ou um cordão sinuoso sobre uma mesa são materializações de curvas. Estas são curvas planas, mas há também as não planas como as bordas de muitas folhas de plantas (LIMA; CARVALHO, 2010, p. 41).

Diante disso, compreendemos que é possível identificar no mundo físico, figuras associadas às diversas dimensões trabalhadas na Geometria como figuras unidimensionais, bidimensionais e tridimensionais. Entretanto, partindo da perspectiva atual do trabalho com Geometria apresentada neste estudo, a figuras unidimensional se configura em um conceito mais abstrato e, consequentemente, mais complexo de ser trabalhado com crianças pequenas. Piaget e Inhelder (1993) afirmam que até os seis anos a criança não reconhece nem representa as formas, além das quais ela consegue reconstruir a partir de suas ações, realizando assim, a abstração das formas ordenadas por suas ações, e não, ou não somente do objeto.

\section{Considerações Finais}

Diante do que foi observado e analisado a partir dos dados, podemos concluir que livros didáticos integrados da EI abordam a Geometria a partir das dimensões constituintes do campo geométrico defendidas neste estudo, como a organização do esquema corporal, a orientação e percepção espaciais e as figuras e formas. Desta forma, podemos confirmar nossa hipótese inicial de que o trabalho com a Geometria, antes apenas focado no estudo das figuras, estaria sendo ampliado, abrangendo o trabalho das competências espaciais.

Contudo, percebemos que mesmo trabalhando a Geometria na perspectiva do ensino das competências espaciais, de um modo geral as coleções identificam/validam como conteúdos matemáticos, explicitando no eixo Espaço e Forma, as figuras bidimensionais e tridimensionais e as transformações geométricas. Portanto, apesar de ser desenvolvido um trabalho com todos os tipos de atividades (categorias) apresentadas neste estudo, as mesmas ainda se configuram em sua maioria, como constituintes de outros eixos de aprendizagem, não sendo realizada, assim, uma abordagem totalmente intencional para a construção da competência espacial. 
Trazemos como contribuição a organização de categorias de atividades de Geometria em livros didáticos, além de oportunizar um olhar sobre suas propostas. Embora os livros didáticos para a EI não sejam adotados em escolas públicas, eles, muitas vezes, são referência para o professor na criação de fichas e de atividades.

A discussão sobre como está sendo proposto o ensino de Geometria nos documentos curriculares ou em estudos anteriores e os resultados do presente estudo nos permitem vislumbrar avanços (ainda que pequenos) quanto à abordagem adotada. Tais avanços vêm indicando a busca (do professor, das instituições responsáveis pelas formações - inicial ou continuada -, das editoras) por alternativas de diversificar a prática pedagógica e os materiais didáticos em uma perspectiva que atenda, de fato, as reais necessidades de aprendizagens dos alunos em cada etapa da escolarização.

\section{Referências}

AGUIAR, Maria Cecília Antunes. O desenvolvimento do conceito de espaço da criança e a educação infantil: esquemas e interações socioafetivas em situações problemas. 2006, 295f. Tese (Doutorado em Educação) - Universidade Federal de Pernambuco, Recife.

ALVES, George de Souza; SAMPAIO, Fábio Ferrentini. O modelo de desenvolvimento do pensamento geométrico de Van Hiele e possíveis contribuições da geometria dinâmica. Revista de Sistemas de Informação da FSMA. $\mathrm{N}^{\circ}$ 5, pp. 69-76, 2010.

BRASIL, Ministério da Educação. Parâmetros Curriculares Nacionais. Matemática. $1^{0}$ e $2^{0}$ ciclos. Secretaria de Ensino Fundamental, 1997.

. Ministério da Educação. Secretaria de Educação Básica. Referencial Curricular Nacional para a Educação Infantil. Vol. 3, Brasília, 1998.

. Ministério da Educação. Secretaria de Educação Básica. Diretrizes Curriculares

Nacionais para a Educação Infantil. Brasília, 2010.

. Proposta da Base Nacional Comum Curricular. Secretaria de Educação Básica, 2017.

CERQUETTI-ABERKANE, Françoise. BERDONNEAU, Catherine. O ensino de matemática na educação infantil. Porto Alegre. Artes Médicas, 1997.

CORDI, Angela. Projeto Eco mirim. Vol.1, 1 ed. - Curitiba: Positivo, 2009.

. Projeto Eco mirim. Vol.2, 1 ed. - Curitiba: Positivo, 2009.

. Projeto Eco mirim. Vol.3, 1 ed. - Curitiba: Positivo, 2009. 
CUSTÓDIO, Iris Aparecida; NACARATO, Adair Mendes. Mobilizando conceitos geométricos nos anos iniciais do ensino fundamental. Revista Educação Matemática em foco. Campina Grande/PB. V6 - No 1 - jan/jun - 2017.

CRUZ, Edneri Pereira. Classificação na Educação Infantil: O que os livros didáticos propõem? 2013, 171f. Dissertação (Mestrado em Educação Matemática e Tecnologica) - Universidade Federal de Pernambuco, Recife.

DANTE, Luiz Roberto. BIANCHINI, Noemi. Projeto Ápis - educação infantil: linguagem, matemática, natureza e sociedade. Vol. 1, 1 ed. - São Paulo: Ática, 2013.

. Projeto Ápis - educação infantil: Projeto Ápis: educação infantil linguagem, matemática, natureza e sociedade. Vol. 2, 1 ed. - São Paulo: Ática, 2013.

. Projeto Ápis - educação infantil: linguagem, matemática, natureza e sociedade. Vol. 3, 1 ed. - São Paulo: Ática, 2013.

LIMA, Paulo. CARVAlHO. João Bosco. Geometria. In. Coleção Explorando o Ensino. Matemática, Ensino Fundamental, v. 17, Brasília: MEC/SEB, 2010.

MODERNA (org.). Buriti Mirim: educação infantil. Vol. 1, 2 ed. - São Paulo: Moderna, 2010. (Coleção Buriti Mirim).

. Buriti Mirim: educação infantil. Vol. 2, 2 ed. - São Paulo: Moderna, 2010. (Coleção Buriti Mirim).

. Buriti Mirim: educação infantil. Vol. 3, 2 ed. - São Paulo: Moderna, 2010. (Coleção Buriti Mirim).

MUNIZ, Aline. A geometria na Educação Infantil. Anais do XI Congresso Nacional de Educação - EDUCARE. Curitiba/PR, 2013.

PIAGET, Jean; INHELDER, Barbel. A representação do espaço na criança. Porto alegre: artes médicas, 1993.

PIRES, Célia; CURI, Edda e CAMPOS, Tânia. Espaço e forma: a construção de noções geométricas pelas crianças das quatro séries iniciais do Ensino Fundamental. PROEM. São Paulo, 2000.

PLAZA, Eliane; CURI, Edda. O espaço e suas relações: uma sequência de atividades em construção. Revista Educação Matemática Pesquisa. São Paulo, v.19, n.2, pp. 99-118, 2017.

RIBEIRO, Aline da Silva. A Geometria na Educação Infantil: Concepções e Práticas de Professores. 2010, 242f. Dissertação (Mestrado em Educação) - Universidade Estadual de São Paulo, São Paulo. 
SILVA, Nathalia; SILVA, Nezilda; PESSOA, Cristiane. Concepções de professoras da Educação Infantil sobre o ensino da Geometria. Caderno de Trabalhos de Conclusão de Curso de Pedagogia. Recife, UFPE. V.16, p. 1-24, 2014.

SOUZA, Simone; FRANCO, Valdeni Soliani. A geometria na educação Infantil: da manipulação Empirista ao concreto Piagetiano. Revista Ciência \& Educação. Vol.18, p.951-963, 2012.

SMOLE, Kátia Cristina Stocco; DINIZ, Maria Ignez; CÂNDIDO, Patrícia (Orgs.). Geometria: Percebendo Espaços, Figuras e Formas. In: Matemática de o a 6 - Figuras e Formas. Porto Alegre: Artmed, 2003.

\section{Biografia Resumida}

Anaelize dos Anjos Oliveira, Mestre em Educação Matemática e Tecnológica pela Universidade Federal de Pernambuco (UFPE) e Pedagoga. Professora dos anos iniciais do Ensino Fundamental da cidade do Recife, Pernambuco, Brasil. Integrante do Grupo de Estudos em Desenvolvimento e Aprendizagem da Matemática na Educação Básica GREDAM/UFPE.

Link do Lattes: http://lattes.cnpq.br/5420334905929216 e-mail: anaelizeoliveira89@gmail.com

Cristiane Azevêdo dos Santos Pessoa, Doutora em Educação pela Universidade Federal de Pernambuco (UFPE). Professora Associada 1 do Departamento de Métodos e Técnicas de Ensino e da Pós-Graduação em Educação Matemática e Tecnológica da UFPE, Recife, Pernambuco, Brasil. Líder do Grupo de Estudos em Desenvolvimento e Aprendizagem da Matemática na Educação Básica - GREDAM/UFPE

Link do Lattes: http://lattes.cnpq.br/3021252548409195

Contato: cristianepessoa74@gmail.com 